http://jmscr.igmpublication.org/home/ ISSN (e)-2347-176x ISSN (p) 2455-0450 crossref DOI: https://dx.doi.org/10.18535/jmscr/v10i1.14

\title{
A Case Report of Walker Warburg Syndrome: A Rare Case with Multiple Uncommon Features
}

\author{
Authors \\ Dr Sohini Shah ${ }^{1}$, Dr Manish Gupta ${ }^{2}$, Dr Kunal Singh ${ }^{3}$, Dr Manish Jaiswal ${ }^{4}$ \\ $1,2,33^{\text {rd }}$ year Postgraduate trainee, Dept of Radiodiagnosis, $\mathrm{KMCH}$ \\ ${ }^{4}$ Assistant professor, Dept of Radiodiagnosis, $\mathrm{KMCH}$
}

\section{Clinical History}

- A full term male neonate born out of consanguineous marriage presented to us on the $3^{\text {rd }}$ day of life with large head and massive hydrocephalus diagnosed during antenatal scan.

- On clinical examination there is generalized hypotonia and macrocephaly.

- On opthalmological examination: White reflex in pupillary areas of $\mathrm{B} / \mathrm{L}$ eyes and micropthalmia of both eyes.

- No significant history of any infection, drug intake, diabetes mellitus radiation exposure during pregnancy.

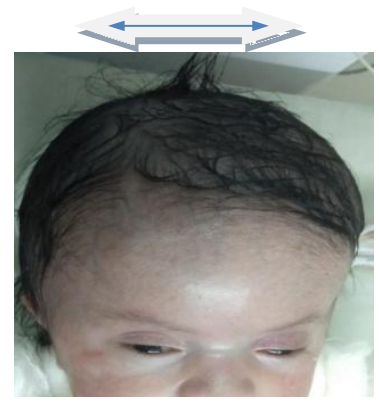

\section{Introduction}

The walker warburg syndrome is rare autosomal recessive disorder. It is characterised by cranial, cerebellar, retinal malformation and congenital muscular dystrophy. It is manifested with cobblestone lissencephaly, agenesis of corpus callosum, hydrocephalus, cerebellar hypoplasia.

\section{Material and Method}

For USG: Philips Epic 5G USG

For CT: GE REVOLUTION ACTs 16 slice MDCT

Department of Radiodiagnosis, Katihar Medical College, Bihar.

\section{Imaging Investigations}

USG Findings

- The patient was examined under Philips Epic 5G USG using 7- $12 \mathrm{MHz}$ linear probe for the orbital scan

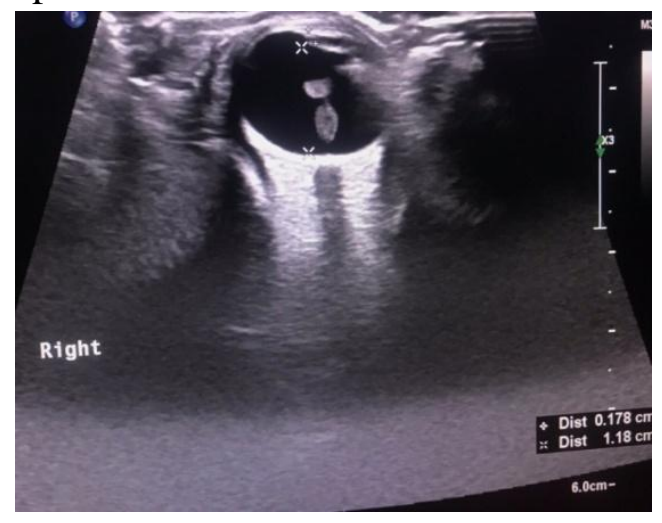




\section{JMSCR Vol||10||Issue||01||Page 69-71||January}

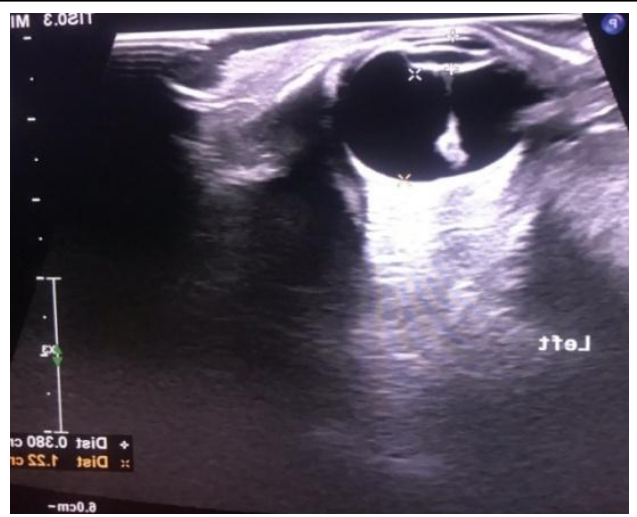

Echogenic band seen in the posterior segment of the both globes extending from posterior surface of the lens to optic nerve head. Right eye $(0.17 \mathrm{x}$ $1.18) \mathrm{cm}$, left eye $(0.38 \times 1.22) \mathrm{cm}$ both eyes are appear apparently smaller in size.

\section{NCCT Head}

Multiplanar non contrast images were acquired using GE REVOLUTION ACTs 16 slice MDCT and reformatted

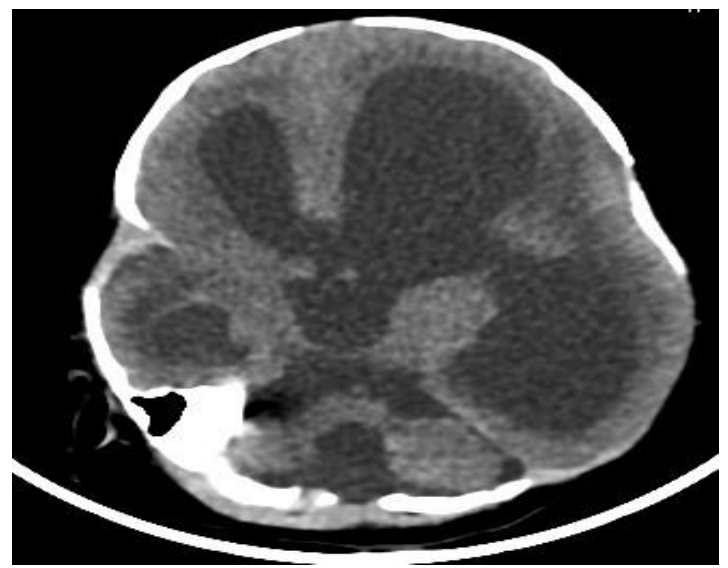

Axial section of brain shows there is gross dilatation of $\mathrm{B} / \mathrm{L}$ lateral ventricles, third ventricle with absent septum pellucidum.

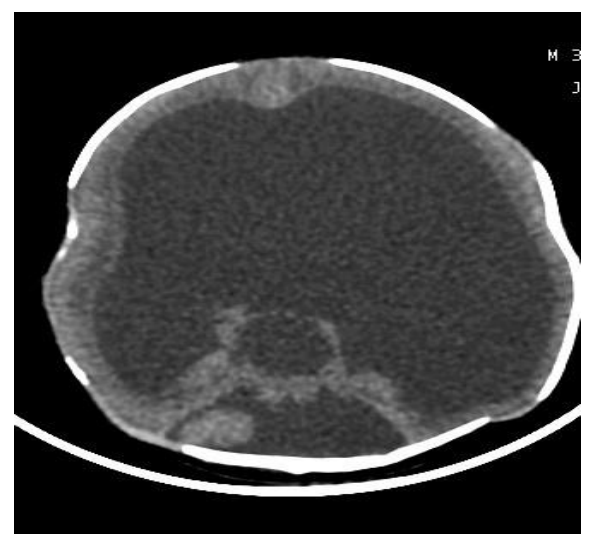

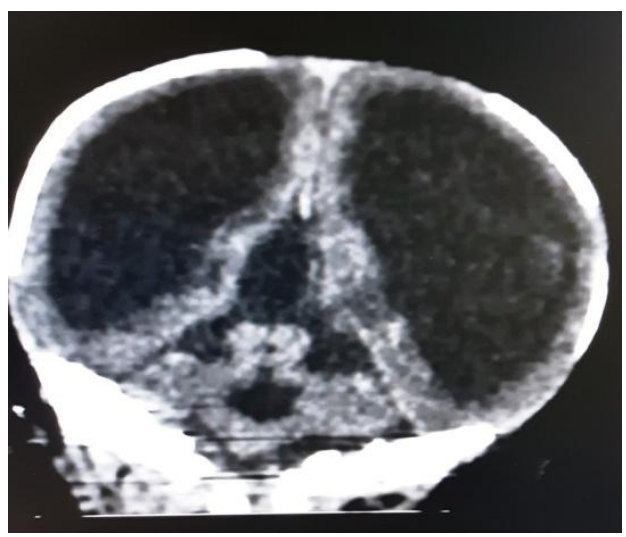

The axial and coronal sections of brain shows thinning of brain parenchyma. Enlarged posterior fossa with high riding tentorium and hypoplastic vermis.
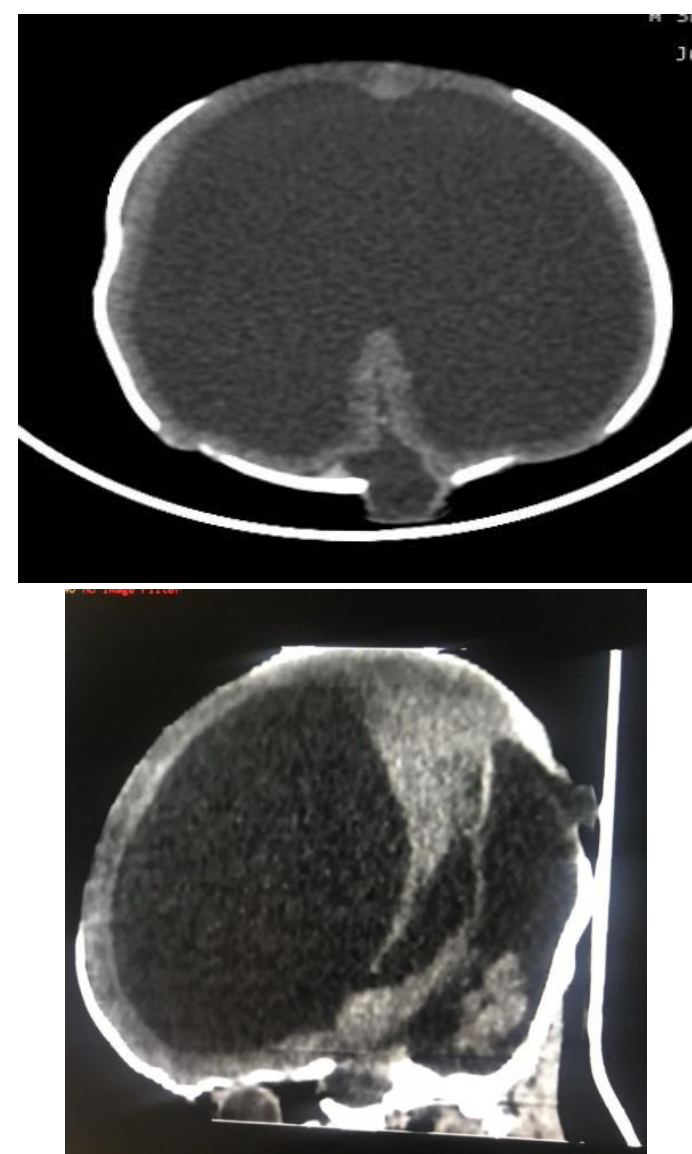

Axial and sagittal sections of brain show CSF containing cystic out pouching protruding out through widened suture in occipital bone $\mathrm{S} / \mathrm{O}$ Meningocele.

\section{Differential Diagnosis}

- Fukuyama congenital muscular dystrophy.

- Congenital muscular dystrophies type 1C

- Congenital muscular dystrophies type 1D 
- Congenital muscular dystrophies without brain and eye abnormalties

- Muscle eye brain disease

\section{Discussion}

- Walker Warburg Syndrome is very rare congenital disorder involving brain, muscle, eye all the three major entities.

- Criteria for diagnosis of WWS include hydrocephalus lissencephaly (agyria/ polymicrogyria), cerebellar malformation, retinal dysplasia and congenital muscular dystrophy and also associated anomalies include Dandy Walker Malformation, cleft lip or palate, posterior encephalocele, occular colobomas, congenital cataracts, and genital abnormalities.

- B scan, CT and MRI imaging use for the occular manifestations of WWS. It include asymmetrical globe size, unilateral buphthamos, retinal detachment, optic nerve hypoplasia, congenital galucoma or microphthalmos and persistent hyaloid artery.

- The overall incidence is unknown. However a survey in north eastern Italy has reported an incidence rate of 1.2 per 100,000 live births.

- The overall prognosis is poor with dies within 1st year of life. There is no proper treatment and management. Only treatment is mainly supportive. Walker Warburg Syndrome is always fatal in infancy.

\section{Conclusion}

All the findings are associated with Walker Warburg syndrome and Dandy- Walker Malformation with gross hydrocephalus, occipital meningocele and micropthalmia of both eyes with persistent hyperplastic primary vitreous.

\section{References}

1. Dobyns WB pagon RA, Armstrong D , Curry CJ, Greenberg F, Grix A, Holmes LB, Laxova R, Michels VV Robinow M , Zimmerman RL. Diagnostic criteria for Walker Warburg Syndrome. Am J Med Genet. 1989;32:195-210.doi:10.1002.

2. Haltia M, Leivo I , Somer H, Pihko H, Paetau A, Kivela BT, Tarkkanen A, Tome F, Engvall E, S antavouri P. Muscle eye brain disease: a neuropathological study. Ann Neurol. 1997;41:173-180.doi:

3. Fukuyama Y, kawarzura M, Haruna H. A pceculiar form of congenital muscular dystrophy : report of fifteen cases. Paediatr Univ Tokyo 1960:4:5-8.

4. Walker AE. Lissencephaly. Arch Neurol Psychiatry 1942:42:13-29. 